Check for updates

The BMJ

Cite this as: $B M J 2020 ; 371: \mathrm{m} 4980$ http://dx.doi.org/10.1136/bmj.m4980 Published: 31 December 2020

\title{
Covid-19: Hospitals in crisis as ambulances queue and staff are asked to cancel leave
}

\section{Elisabeth Mahase}

Hospitals across London and the South East and East of England are struggling to meet rising demand as covid-19 hospital admissions rise to the highest point in the pandemic and the new, more transmissible variant of the virus spreads across the country.

In the face of rising demand, medical leaders have told The BMJ that some hospitals are having to ration oxygen, staff are being asked to work extra shifts, and patients are being treated in the back of ambulances because hospitals have no space.

As at 30 December 22713 people in England were in hospital with covid-19, 1854 of whom were being ventilated. ${ }^{1}$ This is higher than the previous peak of 19000 patients in April. As a result, most of England has now been moved into the highest tier of restrictions, similar to lockdown. ${ }^{2}$

Saffron Cordery, deputy chief executive of NHS Providers, said that in the past seven days the number of patients in hospitals in England had risen by $27 \%$, with an increase of $35 \%$ in critical care beds. "We are in for a very difficult new year," she said.

Alison Pittard, dean of the Faculty of Intensive Care Medicine, said, "It is really bad. London, the East of England, and the South East of England are under immense pressure. Critical care units are overcapacity: there are some units that are at $140 \%$ capacity, so they have patients outside the critical care units. Departments have exhausted their mutual aid in terms of transferring locally because local units are full, so they are looking at transferring patients further afield to make sure they get the care that they need."

She added, "Emergency departments are jam packed because they can't get patients out onto a ward in the hospital, because the ward beds are all full. That has a knock-on effect on ambulances, which are then queuing up outside hospitals because there is no cubical for the patient to go to in the A\&E. It has a huge knock-on effect."

Pittard said that if the public could just see what was happening they "might think twice about partying at New Year and might be encouraged to continue with the 'hands, space, face,' knowing that if they do their bit it will help us get through these next few months."

Meanwhile, the Doctors' Association UK said it was growing "increasingly worried about the current crisis going on in hospitals in the UK."

In a statement the association said, "We are hearing stories of several trusts across London and the South East having to ration oxygen, with target saturations for normal oxygenation having to be dropped as a result of fears of running out. Emails from trusts are being circulated asking already exhausted staff who have worked non-stop during the pandemic to cancel their annual leave, and consider taking on extra shifts.

"The situation has been compared to field hospitals in active war zones, with several patients being seen and treated whilst still in the backs of ambulances, sharing cubicles in the emergency department, or lining up the corridors due to a lack of space."

Zainab Najim, secretary of the Doctors' Association UK and a member of its GP committee, said the government needed to provide urgent guidance and support for the NHS, as it was "crumbling."

\section{NHS England. Covid-19 hospital activity. 31 Dec 2020. https://www.eng- land.nhs.uk/statistics/statistical-work-areas/covid-19-hospital-activity. \\ 2 Kmietowicz Z. Covid-19: England tightens restrictions as NHS struggles to deliver care. BMJ 2020;371:m4972doi: 10.1136/bmj.m4972.}

This article is made freely available for use in accordance with BMJ's website terms and conditions for the duration of the covid-19 pandemic or until otherwise determined by BMJ. You may use, download and print the article for any lawful, non-commercial purpose (including text and data mining) provided that all copyright notices and trade marks are retained. 